\title{
Blue-Laser Readout Properties of Super Resolution Near Field Structure Disc with Inorganic Write-Once Recording Layer
}

\author{
Wei-Chih Hsu ${ }^{1,2}$, Mei-Rurng Tseng ${ }^{1}$, Song-Yeu Tsai ${ }^{1}$ and Po-Cheng KuO ${ }^{2}$ \\ ${ }^{1}$ Materials Research Laboratories, Industrial Technology Research Institute, Bldg. 77, 195-5 Chung Hsing Rd., Section 4, \\ Chutung, Hsinchu, Taiwan 31015, R.O.C. \\ ${ }^{2}$ Institute of Material Science and Engineering, National Taiwan University, No. 1, Roosevelt Rd., Sec. 4, Taipei 106, Taiwan, R.O.C. \\ (Received August 14, 2002; revised manuscript received November 12, 2002; accepted for publication November 14, 2002)
}

A novel inorganic write-once recording material $\mathrm{SbN}_{x}$ (antimony nitride) was proposed for super resolution near field structure (super-RENS) discs. The layer structure is polycarbonate substrate $(0.6 \mathrm{~mm}) / \mathrm{ZnS}-\mathrm{SiO}_{2}(170 \mathrm{~nm}) / \mathrm{AgO} \mathrm{O}_{x}(15 \mathrm{~nm}) /$ $\mathrm{ZnS}-\mathrm{SiO}_{2}(40 \mathrm{~nm}) / \mathrm{SbN}_{x}(25 \mathrm{~nm}) / \mathrm{Ag}(100 \mathrm{~nm}) / \mathrm{UV}$-curing resin/dummy PC substrate $(0.6 \mathrm{~mm})$. The recording layer with highcontrast characteristics enhanced the readout signal, which was compared with that of conventional phase-change materials. The carrier-to-noise ratio (CNR) of $150 \mathrm{~nm}$ mark length was about $44.2 \mathrm{~dB}$ at a readout power of $2.5 \mathrm{~mW}$ using blue laser. A below-diffraction-limited mark length as short as $60 \mathrm{~nm}$ can be readout using blue laser of $405 \mathrm{~nm}$ with a lens having a numerical aperture of 0.65. [DOI: 10.1143/JJAP.42.1005]

KEYWORDS: super-resolution, near-field technique, super-RENS, blue laser, below-diffraction-limited aperture

\section{Introduction}

In conventional optical storage and far-field recording, the theoretical limitation of diffraction is about $0.6 \lambda / \mathrm{NA}$, where $\lambda$ is the wavelength of the laser used and NA is the numerical aperture of the lens. A shorter wavelength with a higher numerical aperture lens can absolutely decrease spot size and significantly increase recording density. However, a higher NA lens implies stricter requirement for the media and drive system. Therefore, many methods have been developed to exceed the diffraction limit for various media such as magneto-optical, phase-change, write-once and readonly media. A super-resolution technique ${ }^{1-6)}$ with a belowdiffraction-limited aperture within the readout spot is one candidate method for increasing recording density by simply inserting a mask layer in the layer structure of a disc without changing laser diode and optical pick-up components. In 1998, Tominaga et al. proposed antimony (Sb)-type super resolution near field structure (super-RENS) disc, which integrated super-resolution with a near-field technique. ${ }^{7)}$ In the layer structure of the Sb-type super-RENS disc, an optical near field is generated at a transparent aperture within the $\mathrm{Sb}$ mask layer and interacts with the recording marks. Therefore, the interface layer between the mask layer and the recording layer should be sufficiently thin within a nearfield region $(<50 \mathrm{~nm})$ to detect signals of below-diffractionlimited mark length $(\sim 60 \mathrm{~nm})$ using a laser beam of $635 \mathrm{~nm}$ wavelength. Conceptually, the Sb-type super-RENS is also called a transparent-aperture-type super-RENS. Tsai and $\mathrm{Lin}^{8)}$ and Liu et al. ${ }^{9)}$ thought that the $\mathrm{SiN}_{x} / \mathrm{Sb} / \mathrm{SiN}_{x}$ sandwich layer works not only as an "aperture" for reducing spot size but also for enhancing other effects of electromagnetic intensity. Physically, the phenomena invole "surface plasmon resonance" (SPR) effects. In 2000, Fuji et al. ${ }^{10)}$ demonstrated that the $\mathrm{AgO}_{x}$-type super-RENS can further enhance near-field signals by using red laser of $635 \mathrm{~nm}$ wavelength. An optical near field is generated around a scattering center within the $\mathrm{AgO}_{x}$ mask layer. When a laser beam with high power is focused on a disc, the $\mathrm{AgO}_{x}$ layer is decomposed rapidly into $\mathrm{Ag}$ and $\mathrm{O}_{2}$ at the central area of the focused spot. Conceptually, the decomposed nano-Ag clusters work as a metallic probe of a near-field scanning optical microscope (NSOM) and such a probe that exists in the disc can detect recording marks at high velocity. The $\mathrm{AgO}_{x}$-type super-RENS is also called a light-scatteringcenter (LSC)-type super-RENS. Blue laser has also been utilized for recording and readout on LSC-type super-RENS discs with a GeSbTe recording layer. ${ }^{11)}$ According to Fuji et al., ${ }^{11)}$ the scattering center could reproduce the minimum mark length of $60 \mathrm{~nm}$. The carrier-to-noise ratios (CNRs) of 100 and $150 \mathrm{~nm}$ marks are about $20 \mathrm{~dB}$ and $32 \mathrm{~dB}$, respectively. It was also found that blue laser could produce a smaller scattering center than red laser. ${ }^{10)}$

The key issues for the super-RENS disc are its low CNR and low thermal stability of small recording marks when the disc is readout at high reading power. Therefore, selecting an appropriate material, which possesses high-contrast reflectivity between the recorded and unrecorded areas and thermal stability for the recording layer, is a good method of solving these problems. We developed the novel inorganic write-once material $\mathrm{SbN}_{x}$, which is suitable for conventional blue-laser recording with a high-data-transfer rate and also as a recording layer material of the LSC-type super-RENS.

\section{Experimental}

We designed the super-RENS blue disc as presented in Fig. 1. The layer structure is $\mathrm{PC}$ substrate $(0.6 \mathrm{~mm}) / \mathrm{ZnS}-$ $\mathrm{SiO}_{2} \quad(170 \mathrm{~nm}) / \mathrm{AgO}_{x} \quad(15 \mathrm{~nm}) / \mathrm{ZnS}-\mathrm{SiO}_{2} \quad(40 \mathrm{~nm}) / \mathrm{SbN}_{x}$ $(25 \mathrm{~nm}) / \mathrm{Ag}(100 \mathrm{~nm}) / \mathrm{UV}$-curing resin/dummy PC substrate

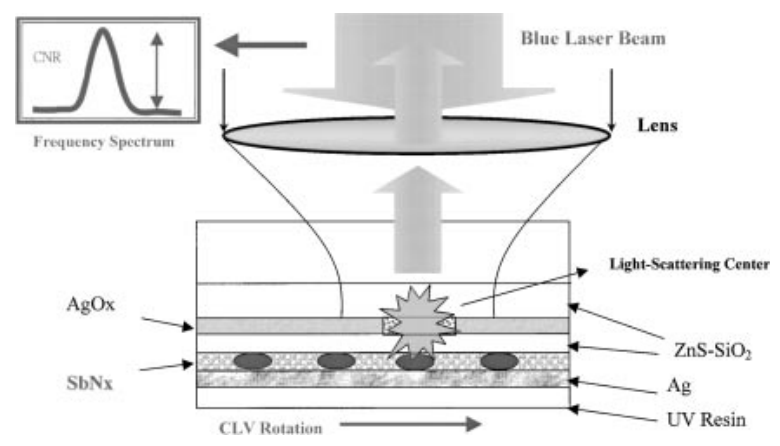

Fig. 1. Layer structure of super-RENS-Blue disc and dynamic testing method. 
$(0.6 \mathrm{~mm})$. The films of all layers were deposited on a polycarbonate substrate by RF-magnetron sputtering at the background pressure of less than $5 \times 10^{-6}$ torr and then at the argon pressure of 2-3 mtorr. The substrate was a conventional pre-grooved polycarbonate disc, $0.6 \mathrm{~mm}$ thick. We used silver oxide as the mask layer deposited by reactive sputtering. Since the light-scattering-center effect is dependent on the oxygen content in the $\mathrm{AgO}_{x}$ mask layer, ${ }^{9)}$ we optimized the partial-pressure ratio of oxygen in the sputtering chamber by controlling the mass-flow ratio of Ar to $\mathrm{O}_{2} \cdot \mathrm{ZnS}-\mathrm{SiO}_{2}$ was deposited as protective and interface layers, which served as spaced mask and recording layers, respectively. An inorganic write-once $\mathrm{SbN}_{x}$ film was used as the recording layer, which was deposited on the sandwich mask layers of $\mathrm{ZnS}-\mathrm{SiO}_{2} / \mathrm{AgO}_{x} / \mathrm{ZnS}-\mathrm{SiO}_{2}$, as shown in Fig. 1. The thicknesses of all layers were controlled precisely, particularly those of the mask layer and interface layer. Silver was sputtered to form a reflective layer. Finally, UV-curing resin was coated on for protection and the dummy PC substrate was bound in order to increase substrate strength. Recording and readout testing of the super-RENS blue disc were performed using a conventional HD-DVD testing system (DDU-1000, Pulstec Co.) with a wavelength of $405 \mathrm{~nm}$ and an NA of 0.65 . The writing marks were recorded on both land and groove areas. The recording mark length was controlled carefully by adjusting the recording power, pulse duration (writing strategy) and linear velocity in consideration of thermal expansion between marks in the recording layer. In detecting the signal of recording marks, the range of reading power was changed from $0.3 \mathrm{~mW}$ to $2.5 \mathrm{~mW}$. The $\mathrm{CNR}$ of the readout signal could be measured using a frequency spectrum analyzer, which was connected with the read channel of the dynamic tester. The thermal properties of $\mathrm{AgO}_{x}$ were investigated using a self-designed transition temperature $\left(T_{x}\right)$ tester, which can measure dependence of the reflectance and transmittance of films on heating temperature from $25^{\circ} \mathrm{C}$ to $650^{\circ} \mathrm{C}$. The optical properties of $\mathrm{AgO}_{x}(15 \mathrm{~nm})$ and $\mathrm{ZnS}-$ $\mathrm{SiO}_{2}(170 \mathrm{~nm}) / \mathrm{AgO}_{x}(15 \mathrm{~nm}) / \mathrm{ZnS}-\mathrm{SiO}_{2}(40 \mathrm{~nm})$ films sputtered on a glass substrate were investigated using a spectrophotometer (Hitachi Co.), which can measure the absorption and transmittance spectrum of the films at wavelengths from $200 \mathrm{~nm}$ to $1000 \mathrm{~nm}$. The sensitivities of recording layers were examined using a commercial static tester (Mediatest, Toptica Co.) of blue laser with a recording wavelength of $399 \mathrm{~nm}$ and reading wavelength of $422 \mathrm{~nm}$. The static tester can measure the reflective change in situ of media or films for the duration of recording pulses.

\section{Results And Discussion}

Figure 2 shows the thermal properties of $\mathrm{AgO}_{x}$ films with various partial-pressure ratios of oxygen to argon, where $\mathrm{O}_{2} /$ $\left(\mathrm{Ar}+\mathrm{O}_{2}\right)$ was varied from 0.2 to 0.7 . As the temperature increased at a ramp of $50^{\circ} \mathrm{C} / \mathrm{min}$, the reflectance suddenly changed between $150^{\circ} \mathrm{C}$ and $170^{\circ} \mathrm{C}$ as shown in Fig. 2(a). The transition temperature $\left(T_{x}\right)$ for each curve is defined as the corresponding temperature at maximum differential of the reflectance-temperature curve. Figure 2(b) shows $T_{x}$ as a function of $\mathrm{O}_{2} /\left(\mathrm{Ar}+\mathrm{O}_{2}\right)$, which was calculated from curves in Fig. 2(a). Variation of $T_{x}$ implies variation in the composition of $\mathrm{AgO}_{x}$ and the composition may become

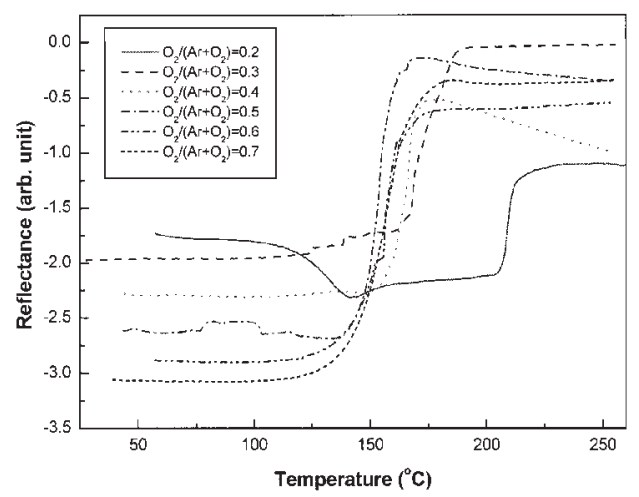

(a)

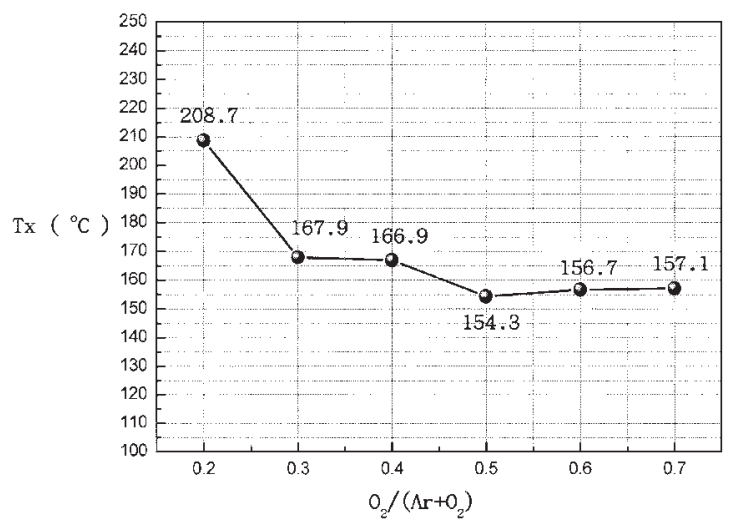

(b)

Fig. 2. Thermal properties of $\mathrm{AgO}_{x}$ mask layer. (a) reflectance as a function of temperature (b) $T_{x}$ as a function of $\mathrm{O}_{2} /\left(\mathrm{Ar}+\mathrm{O}_{2}\right)$.

Ag-rich, $\mathrm{Ag}_{2} \mathrm{O}$-rich or AgO-rich as oxygen content is increased gradually. Detail identification and analysis are necessary. $T_{x}$ is almost between $150^{\circ} \mathrm{C}$ and $170^{\circ} \mathrm{C}$, which agrees with the decomposition temperature $\left(\sim 160^{\circ} \mathrm{C}\right)$ of the reaction $\mathrm{AgO}_{x} \rightarrow \mathrm{Ag}+x / 2 \mathrm{O}_{2}$. Figure 3 shows the absorption spectrum of single-layer $\mathrm{AgO}_{x}(15 \mathrm{~nm})$ and sandwichlayer $\mathrm{ZnS}-\mathrm{SiO}_{2}(170 \mathrm{~nm}) / \mathrm{AgO}_{x}(15 \mathrm{~nm}) / \mathrm{ZnS}-\mathrm{SiO}_{2}(40 \mathrm{~nm})$. Both films have adequate absorption at specific wavelengths of $405 \mathrm{~nm}$ and $650 \mathrm{~nm}$. As the super-RENS disc is readout at high power, the heat source for decomposition into Ag nano clusters should come directly from the absorption of laser and partially from thermal diffusion of the recording layer, which is only $40 \mathrm{~nm}$ away from the $\mathrm{AgO}_{x}$ mask layer.

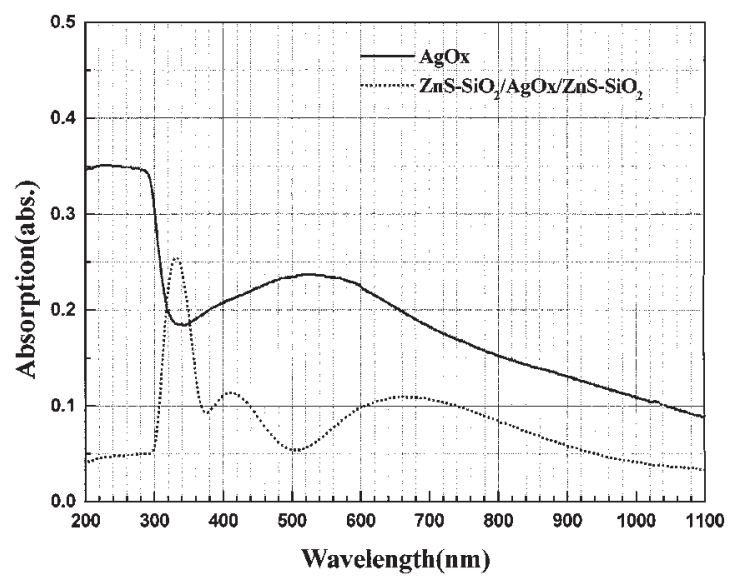

Fig. 3. Absorption spectra of $\mathrm{AgO}_{x}(15 \mathrm{~nm})$ and $\mathrm{ZnS}-\mathrm{SiO}_{2}(170 \mathrm{~nm}) /$ $\mathrm{AgO}_{x}(15 \mathrm{~nm}) / \mathrm{ZnS}-\mathrm{SiO}_{2}(40 \mathrm{~nm})$ films. 


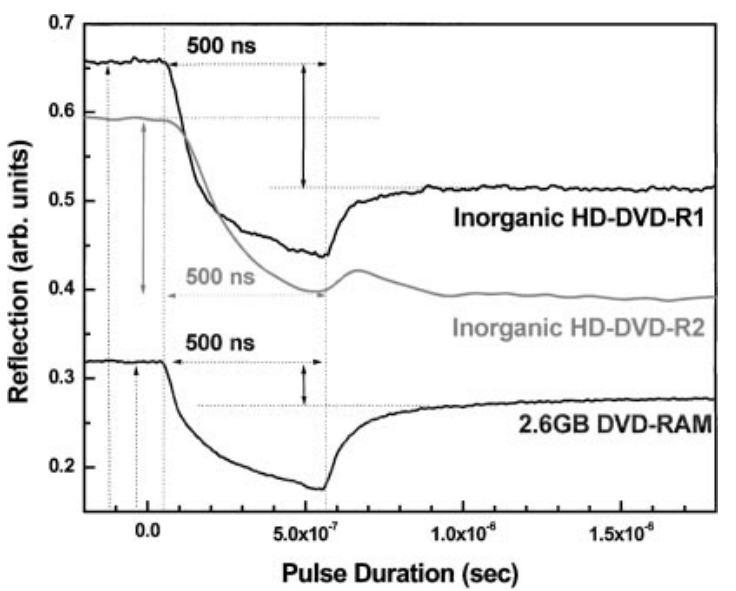

Fig. 4. Comparison of recording sensitivities between $\mathrm{SbN}_{x}$ and $2.6 \mathrm{~GB}$ DVD-RAM discs by static tester of blue laser.

Figure 4 shows the recording sensitivities of inorganic write-once material $\mathrm{SbN}_{x}$ and phase change material GeSbTe for commercial 2.6 GB DVD-RAM, which were examined using a static tester. The difference between inorganic HD-DVD-R1 and inorganic HD-DVD-R2 is the layer structure. The layer structure of the inorganic HDDVD-R2 disc was modified for rapid cooling. At the end of the writing-power pulse, the cooling performance of the inorganic HD-DVD-R2 disc is more efficient than that of the inorganic HD-DVD-R1 disc and can increase the reflective contrast between before and after recording. Reflective

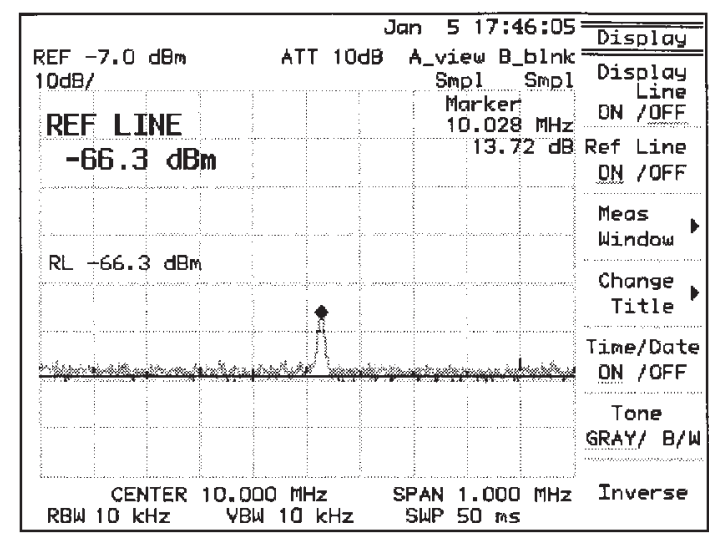

Mark length $=75 \mathrm{~nm}$

Fig. 5. Frequency spectrum of $75 \mathrm{~nm}$ mark length, which was readout at $P_{\mathrm{r}}=2.5 \mathrm{~mW}$.

contrasts of both inorganic HD-DVD-R discs are much higher than that of the commercial 2.6 GB DVD-RAM disc using blue laser.

Theoretically, the resolution limit of recording marks is defined as half of the diffraction limit $(\sim 160 \mathrm{~nm}$ in this test system). A mark length as short as $75 \mathrm{~nm}$ can be readout by the super-RENS technique and the readout CNR of a $75 \mathrm{~nm}$ mark train is about $13.7 \mathrm{~dB}$ at a readout power of $2.5 \mathrm{~mW}$, as shown in Fig. 5.

Figure 6(a) shows the frequency spectrum of the $150 \mathrm{~nm}$

(a) Mark length $=150 \mathrm{~nm}$

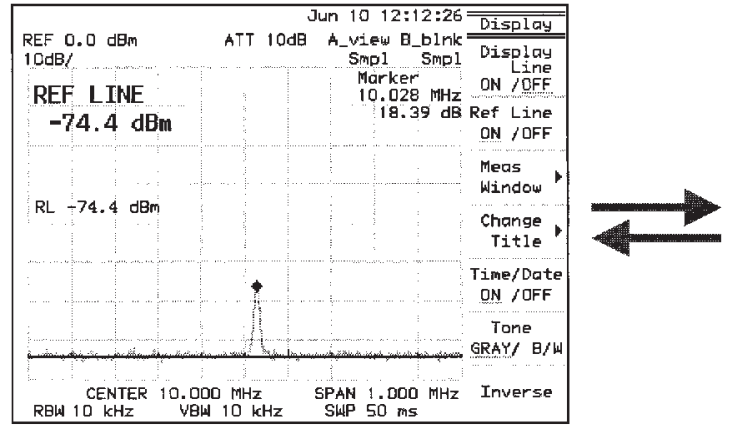

$\operatorname{Pr}=0.4 \mathrm{~mW}$

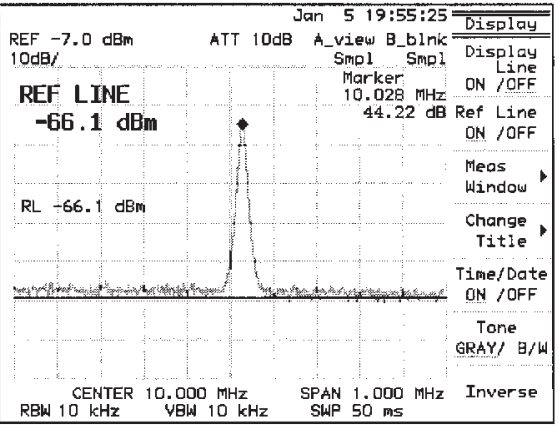

$\operatorname{Pr}=2.5 \mathrm{~mW}$

(b) Mark length $=100 \mathrm{~nm}$

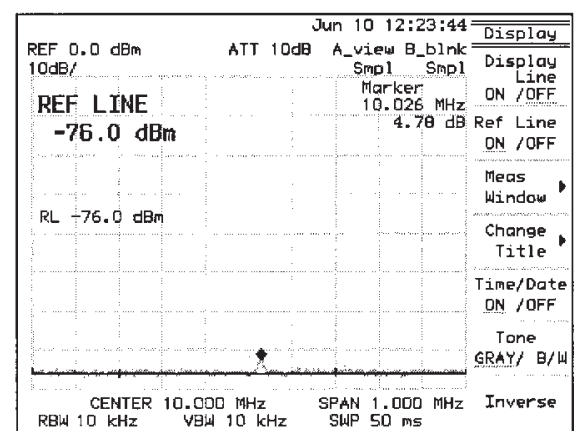

$\operatorname{Pr}=0.4 \mathrm{~mW}$

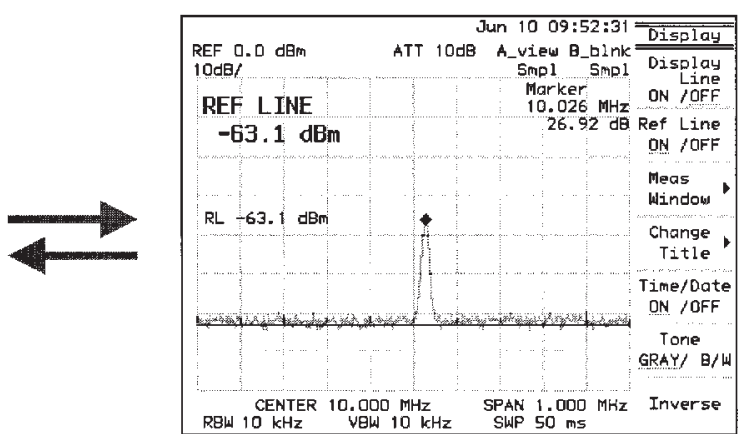

$\mathrm{Pr}=2.5 \mathrm{~mW}$

Fig. 6. Frequency spectra of (a) $150 \mathrm{~nm}$ mark length and (b) $100 \mathrm{~nm}$ mark length, which were readout at high $\left(P_{\mathrm{r}}=2.5 \mathrm{~mW}\right)$ and low $\left(P_{\mathrm{r}}=0.4 \mathrm{~mW}\right)$ powers. 


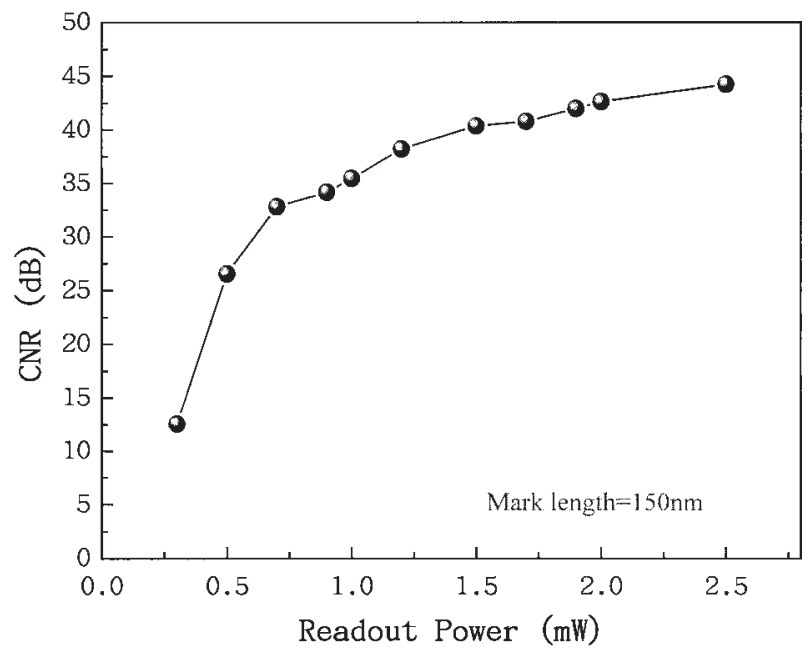

Fig. 7. Relationship between CNR of $150 \mathrm{~nm}$ mark train and readout power.

mark train, which was readout at high $\left(P_{\mathrm{r}}=2.5 \mathrm{~mW}\right)$ and low $\left(P_{\mathrm{r}}=0.4 \mathrm{~mW}\right)$ reading powers. The readout CNR is as high as $44 \mathrm{~dB}$ at a readout power of $2.5 \mathrm{~mW}$. Figure $6(\mathrm{~b})$ shows the frequency spectrum of the $100 \mathrm{~nm}$ mark train, which was readout at high $\left(P_{\mathrm{r}}=2.5 \mathrm{~mW}\right)$ and low $\left(P_{\mathrm{r}}=0.4 \mathrm{~mW}\right)$ reading powers. The readout $\mathrm{CNR}$ is as high as $27 \mathrm{~dB}$ at a readout power of $2.5 \mathrm{~mW}$. Figure 7 shows the relationship between CNR of the $150 \mathrm{~nm}$ mark train and readout power. Generally, higher CNR could be readout as the readout power is increased. The CNR would increase at a critical reading power of $\sim 0.5 \mathrm{~mW}$ then would saturate with further increase in readout power, as shown in Fig. 7. Contrariwise, the CNR would be diminished at following decreasing readout power. Therefore, the characteristics of readout CNR depend on reading power and appropriate readout power is necessary for generating the surface plasmon resonance. However, much higher reading power may erase the recording mark and damage the mask layer because of a large amount of thermal accumulation. In consideration of thermal stability, an adequate material for the recording layer of the super-RENS blue disc should have high transition temperature $\left(T_{x}\right)$.

Figure 8 shows the relationship between CNR and mark length of the super-RENS blue disc, which were readout at 0.4, 2.0 and $2.5 \mathrm{~mW}$. Generally, the CNR signal would be reduced as decreasing recording mark length and higher readout power $(>0.4 \mathrm{~mW})$ is necessary for reading the mark length less than $100 \mathrm{~nm}$. A mark length as short as $60 \mathrm{~nm}$ could be readout at $P_{\mathrm{r}}=2.5 \mathrm{~mW}$. The below-diffractionlimited mark lengths of $100 \mathrm{~nm}$ to $170 \mathrm{~nm}$ could be readout at a very low power of $0.4 \mathrm{~mW}$.

Figure 9 shows the comparison between the super-RENSblue discs with $\mathrm{SbN}_{x}$ and that with GeSbTe for recordinglayer materials. Since the $\mathrm{SbN}_{x}$ has higher contrast between the recorded mark and the unrecorded area than GeSbTe, the CNR of the super-RENS disc with $\mathrm{SbN}_{x}$ is much higher than that of the super-RENS disc with GeSbTe when reading every mark length from $60 \mathrm{~nm}$ to $240 \mathrm{~nm}$. Theoretically, surface plasmons are not only generated on a light-scattering center but also along single-tone mark trains below the diffraction limit and along period structures of metal films.

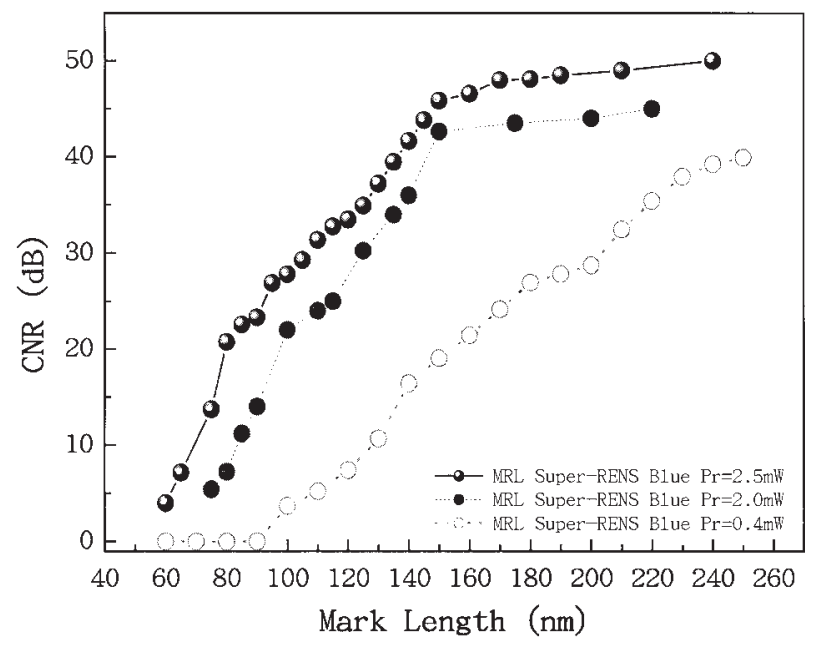

Fig. 8. Relationship between CNR and mark length of super-RENS-Blue Disc, which was readout at $P_{\mathrm{r}}=0.4 \mathrm{~mW}, 2.0 \mathrm{~mW}$ and $2.5 \mathrm{~mW}$.

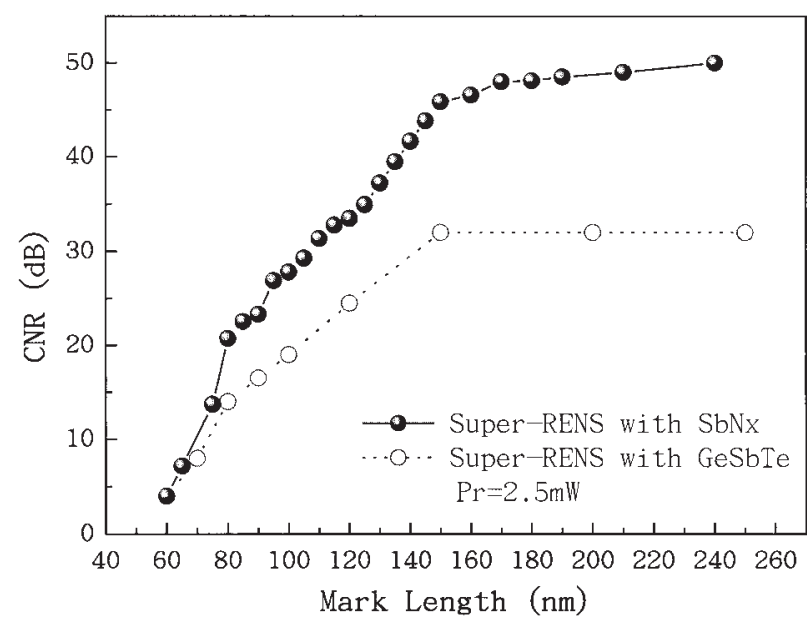

Fig. 9. Comparison between super-RENS blue disc with $\mathrm{SbN}_{x}$ and that with GeSbTe for recording-layer materials.

As the light-scattering center is sufficiently close to the recording layer with small marks, the near-field electromagnetic interaction could be much more enhanced. Therefore, if the contrast in optics, morphology and composition of recording layer could be increased, the signal would be further enhanced.

\section{Conclusion}

We have investigated the blue-laser readout properties of the super-RENS disc with the inorganic write-once recording layer $\mathrm{SbN}_{x}$. Since the contrast of the recording layer is high, the CNR was as high as $44.2 \mathrm{~dB}$ at $150 \mathrm{~nm}$ mark length. The $60 \mathrm{~nm}$ mark length can be readout at a reading power of $2.5 \mathrm{~mW}$, which exceeds the limitation of diffraction.

1) M. Kuroda: Int. Symp. Optical Memory Tech. Dig. (1995) We-C1.

2) Y. Kasami, K. Yasuda, M. Ono, A. Fukumoto and M. Kaneko: Jpn. J. Appl. Phys. 35 (1996) 423.

3) K. Yasuda, M. Ono, K. Aratani, A. Fukumoto and M. Kaneko: Jpn. J. Appl. Phys. 32 (1993) 5210. 
4) T. Shintani, K. Moritani, A. Hirotsune, M. Terao, H. Yamamoto and T. Naito: Joint Magneto-Optical Recording Int. Symp./Int. Symp. Optical Memory Tech. Dig. (1997) Th-PD03.

5) M. Hatakeyama, T. Ando, K. Tsujita, K. Oishi and I. Ueno: Joint Int Symp. Optical Memory/Optical Data Storage Tech. Dig. (1999) p. 172.

6) W. C. Hsu, S. Y. Tsai, P. C. Kuo, M. R. Tseng, S. P. Hsu, T. T. Hung and C. J. Chang: Proc. SPIE 4342 (2001) 332.

7) J. Tominaga, T. Nakano and N. Atoda: Appl. Phys. Lett. 73 (1998)
2078.

8) D. P. Tsai and W. C. Lin: Appl. Phys. Lett. 77 (2000) 1413.

9) W. C. Liu, C. Y. Wen, K. H. Chen, W. C. Lin and D. P. Tsai: Appl. Phys. Lett. 78 (2001) 685.

10) H. Fuji, J. Tominaga, L. Men, T. Nakano, H. Katayama and N. Atoda: Jpn. J. Appl. Phys. 39 (2000) 980.

11) H. Fuji, J. Tominaga, H. Katayama and N. Atoda: Int. Symp. Optical Memory Tech. Dig. (2000) Fr-J-34. 